\title{
Sexual Behaviors During COVID-19: The Potential Risk of Transmission
}

\author{
Massimiliano Cipriano $^{1} \cdot$ Andrea Giacalone $^{2} \cdot$ Enzo Ruberti $^{3}$ (i)
}

Received: 14 May 2020 / Revised: 28 May 2020 / Accepted: 30 May 2020 / Published online: 5 June 2020

(c) Springer Science+Business Media, LLC, part of Springer Nature 2020

On 31 December 2019, Chinese health authorities reported a cluster of pneumonia cases of unknown etiology in the city of Wuhan (Hubei province, China). On 9 January 2020, the China CDC (the Chinese Center for Disease Control and Prevention) identified a novel coronavirus (provisionally named 2019-nCoV) as the causative agent for these cases and also confirmed human-to-human transmission of the virus. On 11 March 2020, the World Health Organization (WHO) announced that the respiratory disease caused by Sars-Cov-2 was a pandemic (Epidemiology for Public Health-Istituto Superiore di Sanità, 2020).

The most common transmission routes of novel Coronavirus include direct transmission (cough, sneeze, and droplet inhalation transmission) and contact transmission (contact with oral, nasal, and eye mucous membranes) (Lu, Liu, $\&$ Jia, 2020). Respiratory droplets and physical intimacy, which implies being inside someone's personal space (e.g., hugging, kissing, caressing), are the two main transmission routes of SARS-CoV-2 (Chen et al., 2020b; Huang et al., 2020), but evidence for a fecal-oral transmission route has also been shown (Kanne, 2020; Xiao et al., 2020). However, vertical and sexual transmissions among female patients have not been recognized (Chen et al., 2020a; Cui et al., 2020). SARS-CoV-2 entry into target cells is likely mediated by the interaction between the viral Spike (S) protein and cellular Angiotensin-Converting Enzyme 2 (ACE2). ACE2 is expressed in multiple organ systems, including Type II alveolar cells of the lungs, intestine, heart, kidney, testis, and in the glandular cells of rectal epithelium (Li et al., 2003; Xiao et al., 2020; Zhou et al., 2020).

Enzo Ruberti

enzo.ruberti@uniroma1.it

1 Department of Laparoscopic Surgery, Umberto I General Hospital, Medical School Sapienza University, Rome, Italy

2 Industrial Engineering Technologies for Sports Medicine and Rehabilitation, University Tor Vergata, Rome, Italy

3 Department of Human Neuroscience, Sapienza University of Rome, Viale dell'Università 30, 00185 Rome, Italy
Several studies have demonstrated the presence of viral RNA in the feces of patients affected by COVID-19, suggesting the possibility of viral transmission through the oral-fecal route (Nouri-Vaskeh \& Alizadeh, 2020; Zhang et al., 2020). Furthermore, there is evidence proving that fecal tests continue to be positive even after the respiratory specimens become negative (Tian, Rong, Nian, \& He, 2020).

Studies aimed at investigating the potential mechanisms underlying SARS-CoV-2 transmission and infection at the level of the oral cavity have shown that ACE2 is expressed by the mucosal epithelial cells. The expression of this molecule is higher at the tongue level than in gingival and buccal tissues, indicating it as a possible route of infection (Xu et al., 2020). Moreover, live viruses were detected in the saliva of infected individuals (To et al., 2020).

In order to explore the possibility of sexual transmission, the presence of SARS-CoV-2 was tested in vaginal fluid and semen of SARS-CoV-2-positive patients. In one study (Pan et al., 2020), Sars-CoV-2 was detected in semen samples of 34 Chinese men recovering from COVID-19 with milder symptoms. In two other studies, one in which 35 female COVID-19 patients were recruited and who came from different geographical areas of Wuhan (Cui et al., 2020) and another in which were 10 postmenopausal woman with severe COVID-19 were recruited (Qiu et al., 2020), Sars$\mathrm{CoV}-2$ was detected in vaginal fluids. In these studies, SARS$\mathrm{CoV}-2$ was not found either in semen or in vaginal fluids of positive cases.

This does not exclude the possibility of viral transmission through sexual behavior (e.g., oral/anal contacts). Indeed, viral particles may be transmitted through oral sex and use of saliva as a lubricant. This is supported, as previously described, by the shedding of viral particles through the saliva and the feces and the presence of ACE2 receptors on the epithelium lining the oral cavity and the rectum.

Physicians should inform their patients about these risk behaviors in order to avoid further spreading of the virus. The importance of increasing awareness on less common transmission routes stems from the high number of contagious persons, including asymptomatic individuals and patients 
with double-negative oro/nasopharyngeal swab, but still potentially contagious (persistent fecal elimination of the virus).

Author Contributions $M C$ conducted the research and wrote the first draft of the manuscript. $A G$ supported manuscript revisions. $E R$ supported the research.

\section{Compliance with Ethical Standards}

Conflict of interest We declare no competing interests

\section{References}

Chen, H., Guo, J., Wang, C., Luo, F., Yu, X., Zhang, W., et al. (2020a). Clinical characteristics and intrauterine vertical transmission potential of COVID-19 infection in nine pregnant women: A retrospective review of medical records. Lancet, 395, 809-815.

Chen, N., Zhou, M., Dong, X., Qu, J., Gong, F., Han, Y., et al. (2020b). Epidemiological and clinical characteristics of 99 cases of 2019 novel coronavirus pneumonia in Wuhan, China: A descriptive study. Lancet, 395, 507-513.

Cui, P., Chen, Z., Wang, T., Dai, J., Zhang, J., Ding, T., et al. (2020). Clinical features and sexual transmission potential of SARS-CoV-2 infected female patients: A descriptive study in Wuhan, China. medRxiv.

Epidemiology for Public Health-Istituto Superiore di Sanità. (2020). epicentro.iss.it/en/coronavirus/sars-cov-2-international-outbreak.

Huang, C., Wang, Y., Li, X., Ren, L., Zhao, J., Hu, Y., et al. (2020). Clinical features of patients infected with 2019 novel coronavirus in Wuhan, China. Lancet, 395, 497-506.

Kanne, J. P. (2020). Chest CT findings in 2019 novel coronavirus (2019$\mathrm{nCoV}$ ) infections from Wuhan, China: Key points for the radiologist. Radiology, 295, 16-17.

Li, W., Moore, M. J., Vasilieva, N., Sui, J., Wong, S. K., Berne, M. A., et al. (2003). Angiotensin-converting enzyme 2 is a functional receptor for the SARS coronavirus. Nature, 426, 450-454.
Lu, C.-W., Liu, X-F., \& Jia, Z-F. (2020). 2019-nCoV transmission through the ocular surface must not be ignored. Lancet, 395(10224), e39.

Nouri-Vaskeh, M., \& Alizadeh, L. (2020). Fecal transmission in COVID-19: A potential shedding route. Journal of Medical Virology. https://doi.org/10.1002/jmv.25816.

Pan, F., Xiao, X., Guo, J., Song, Y., Li, H., Patel, D. P., et al. (2020). No evidence of SARS-CoV-2 in semen of males recovering from COVID-19. Fertility and Sterility. https://doi.org/10.1016/j.fertn stert.2020.04.024.

Qiu, L., Liu, X., Xiao, M., Xie, J., Cao, W., Liu, Z., et al. (2020). SARS$\mathrm{CoV}-2$ is not detectable in the vaginal fluid of women with severe COVID-19 infection. Clinical Infectious Diseases. https://doi. org/10.1093/cid/ciaa375/5815295.

Tian, Y., Rong, L., Nian, W., \& He, Y. (2020). Review article: Gastrointestinal features in COVID-19 and the possibility of faecal transmission. Alimentary Pharmacology \& Therapeutics, 51, 843-851.

To, K. K.-W., Tsang, O. T.-Y., Yip, C. C.-Y., Chan, K.-H., Wu, T.-C., Chan, J. M. C., et al. (2020). Consistent detection of 2019 novel coronavirus in saliva. Clinical Infectious Diseases. https://doi. org/10.1093/cid/ciaa149.

Xiao, F., Tang, M., Zheng, X., Liu, Y., \& Shan, H. (2020). Evidence for gastrointestinal infection of SARS-CoV-2. Gastroenterology, 158(6), 1831-1833.

Xu, H., Zhong, L., Deng, J., Peng, J., Dan, H., Zeng, X., et al. (2020). High expression of ACE2 receptor of 2019-nCoV on the epithelial cells of oral mucosa. International Journal of Oral Science, 12, 8.

Zhang, W., Du, R.-H., Li, B., Zheng, X.-S., Yang, X.-L., Hu, B., et al. (2020). Molecular and serological investigation of 2019-nCoV infected patients: Implications of multiple shedding routes. Emerging Microbes \& Infections, 9(1), 386-389.

Zhou, P., Yang, X. L., Wang, X. G., Hu, B., Zhang, L., Zhang, W., et al. (2020). A pneumonia outbreak associated with a new coronavirus of probable bat origin. Nature, 579, 270-273.

Publisher's Note Springer Nature remains neutral with regard to jurisdictional claims in published maps and institutional affiliations. 